\title{
OXIDATION \& COATING EVOLUTION IN ALUMINIZED FOURTH GENERATION BLADE ALLOYS
}

\author{
I.M. Edmonds ${ }^{1}$, H.E. Evans ${ }^{1}$, C.N. Jones ${ }^{2}$ \\ ${ }^{1}$ Metallurgy and Materials, Rolls-Royce UTP, University of Birmingham, Edgbaston, Birmingham. B15 2TT. UK \\ ${ }^{2}$ Rolls-Royce Plc, PO Box 31, Derby. DE24 8BJ. UK.
}

Keywords: Fourth generation superalloys; oxidation; aluminide coating; Ru additions

\begin{abstract}
Oxidation tests have been undertaken in air on two aluminized experimental fourth-generation Ni-based superalloys containing, respectively, 3 and $5 \mathrm{wt} \% \mathrm{Ru}$, in order to detail the effect of $\mathrm{Ru}$ on oxidation characteristics and coating evolution. A Ru-free, aluminide coated third generation alloy (CMSX-10K) was also included in the test programme which used temperatures covering the range $750-1100^{\circ} \mathrm{C}$.

Aluminization has been shown to effectively minimize the effect of alloy chemistry on oxidation rate constants over the timescales studied, when compared to the uncoated substrates. Aluminization also prevents the formation of internal oxidation pits in the coated $\mathrm{Ru}$-bearing alloys after oxidation at $750^{\circ} \mathrm{C}$. Increasing $\mathrm{Ru}$ marginally decreased the mass-gain due to oxidation of the three aluminized alloys at all temperatures. At $750^{\circ} \mathrm{C}$ the rate of oxidation of aluminized specimens was controlled not by the formation of aluminas but by that of the spinel phase $\mathrm{Ni}(\mathrm{Al}, \mathrm{Cr})_{2} \mathrm{O}_{4}$. Interestingly, each of the three aluminized alloys produced a different coating - substrate microstructural interaction after exposure at $1100^{\circ} \mathrm{C}$, with $\mathrm{Ru}$ increasing the propensity for secondary reaction zone (SRZ) formation. SRZs are characterized by a weak high angle boundary which can lead to localized coating loss (and hence increased section loss). Ru also underwent long range diffusion, concentrating in the $\beta-\mathrm{NiAl}$ phase in solution, and where SRZ was present resulted in the precipitation of $\beta 2-\mathrm{RuAl}$ within the $\gamma$ ' SRZ matrix in addition to the topologically close-packed precipitates (TCPs).
\end{abstract}

\section{Introduction}

Fourth generation Ni-based superalloys are characterized by the inclusion of the platinum group refractory metal, $\mathrm{Ru}$, in concentrations between $2-5$ wt. $\%$, in addition to $\sim 6$ wt. $\%$ Re. They offer superior high temperature microstructural stability compared to preceding generations. Ru improves creep directly up to intermediate temperatures but more importantly suppresses topologically close-packed phase (TCP) precipitation within the substrate [1]. Given the rising turbine entry temperatures sought by engine manufacturers for efficiency gains, oxidation is becoming a more and more prevalent failure mechanism. However, generally fourth generation alloys are significantly poorer in oxidation than second generation alloys such as CMSX$4[2,3]$. It is desirable for intermediate pressure (IP) turbine blades to be uncoated but since the oxidation performance of fourth generation alloys may not be acceptable it is necessary to evaluate simple economically viable coatings, such as aluminides. Currently few detailed studies have been done to understand the effect of $\mathrm{Ru}$, and the balance of extra refractory elements it affords, on oxidation and coating interaction $[3,4]$.

\section{Experimental Procedures}

In this present study the oxidation performance and coating evolution of two aluminide coated experimental fourth-generation alloys, containing either 3 or 5 wt.\% Ru (different only by direct substitution of $\mathrm{Ni}$ ) was compared with that of a commercial $\mathrm{Ru}-$ free third generation alloy, CMSX10-K. The compositions of the alloy substrates are given in Table I, and in all cases are noted to be borderline alumina formers according to the criteria determined by Giggins and Pettit [5].

Single crystal pencil castings of the two experimental alloys and the third generation alloy were cast at the Rolls-Royce Plc Precision Casting Facility. Castings were grown in the <001> direction with generally less than $\pm 12^{\circ}$ misorientation. The cast bars were conventionally heat treated before grit blasting using alumina grit. The heat-treated and grit-blasted bars were cut using $\mathrm{SiC}$ blades to provide oxidation specimens measuring $8-14 \mathrm{~mm}$ diameter and 6-15 mm thick. Aluminization was performed at Turbine Surface Technologies Ltd by pack cementation using an 'inward grown' low temperature high activity method carried out at $860-930^{\circ} \mathrm{C}$ for $4-9 \mathrm{~h}$. Final heat treatment was $1 \mathrm{~h}$ at $1100^{\circ} \mathrm{C}$ in a low pressure $\mathrm{Ar}$ atmosphere, and this was followed by secondary aging.

Table I. The composition of the cast third and fourth generation alloys determined by XRF.

\begin{tabular}{|c|c|c|c|c|c|c|}
\hline \multirow{2}{*}{ Alloy } & \multicolumn{2}{|c|}{$\begin{array}{c}\text { CMSX10-K } \\
\text { (RR3000) }\end{array}$} & \multicolumn{2}{c|}{$\begin{array}{c}\text { UCSX2: } \\
\text { 3wt\%Ru }\end{array}$} & \multicolumn{2}{c|}{$\begin{array}{c}\text { UCSX2: } \\
\text { 5wt\%Ru }\end{array}$} \\
\cline { 2 - 7 } & wt-\% & at-\% & wt-\% & at-\% & wt-\% & at-\% \\
\hline $\mathrm{Ni}$ & bal. & bal. & bal. & bal. & bal. & bal. \\
\hline $\mathrm{Co}$ & 3.3 & 3.5 & 8.2 & 9.1 & 8.5 & 9.6 \\
\hline $\mathrm{Cr}$ & 2.3 & 2.8 & 3.1 & 3.9 & 3.3 & 4.2 \\
\hline $\mathrm{Mo}$ & 0.4 & 0.3 & 1 & 0.7 & 1 & 0.7 \\
\hline $\mathrm{W}$ & 5.5 & 1.9 & 8 & 2.9 & 8 & 2.9 \\
\hline $\mathrm{Re}$ & 6.3 & 2.1 & 6.8 & 2.4 & 6.5 & 2.3 \\
\hline $\mathrm{Ru}$ & - & - & 3.1 & 2.0 & 5.3 & 3.5 \\
\hline $\mathrm{Al}$ & 5.8 & 13.6 & 5.3 & 12.9 & 5.4 & 13.3 \\
\hline $\mathrm{Ti}$ & 0.22 & 0.3 & - & - & - & - \\
\hline $\mathrm{Ta}$ & 8.4 & 2.9 & 7.8 & 2.8 & 8.1 & 3.0 \\
\hline $\mathrm{Nb}$ & 0.1 & 0.1 & - & - & - & - \\
\hline $\mathrm{Hf}$ & 0.03 & 0.01 & 0.1 & 0.04 & 0.1 & 0.04 \\
\hline
\end{tabular}

Samples were isothermally exposed at 750,900 and $1100^{\circ} \mathrm{C}$ in static laboratory air for 200,500 or 1000 hours. Net mass gain kinetics of both bare and aluminized samples were determined by periodic removal of a specimen, weighing and re-inserting for 
further exposure. Reproducibility in weighing is approximately \pm $50 \mu \mathrm{g}$. Spalled oxide was not included in these measurements. The oxide morphology and coating evolution was investigated by FEG-SEM, EDX, electron backscattered diffraction (EBSD) and the oxide species present on aluminized CMSX-10K were identified by XRD.

The surfaces of the oxidized specimens were examined by SEM/EDX before mounting. Prior to sectioning, specimens were either Ni plated or vacuum impregnated with epoxy resin, in which case no Ni-plating was required. The sections were mounted in acrylic resin of low shrinkage and coarse polished using standard procedures. Final polishing was completed using a Struers MD-Chem disc with OP-A acidified alumina suspension or OP-S activated colloidal silica. SEM examination was undertaken using either a Jeol 7000F FEGSEM, with Oxford Instruments EDX/WDX/EBSD capability, or a Philips XL30 FEGSEM with EDAX elemental analysis system. XRD was performed on a Philips X'Pert X-ray Diffractometer $(\mathrm{Cu} \mathrm{K} \alpha$ source) over the range $10^{\circ}<2 \theta<100^{\circ}$. The PDF-2 database [6] was used to evaluate the diffractograms. Image analysis was completed using ImageJ 1.38X.

\section{As-Coated Microstructures}

The coating morphology of the as-received aluminized alloys were examined by SEM/EDX as shown in Figure 1. CMSX10-K, UCSX2-3Ru and UCSX2-5Ru showed a mean $\beta$-NiAl thickness of 41.5 (standard deviation, $\sigma=1.6), 37.7(\sigma=1.1)$ and $35.5(\sigma=$ 1.8) $\mu \mathrm{m}$ respectively. The mean interdiffusion zone (IDZ) depth measured 9.1 $(\sigma=0.4), 9.2(\sigma=0.3)$ and $8.3(\sigma=0.5) \mu \mathrm{m}$ respectively. In the case of CMSX-10K the small secondary diffusion zone (SDZ) was included in this measurement.
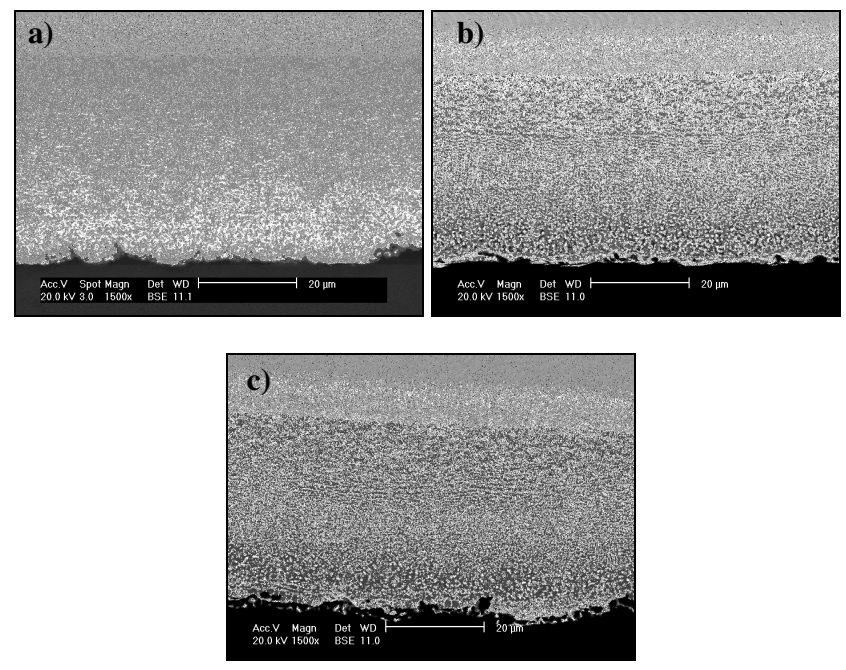

Figure 1. Backscattered SEM images of as-received aluminide coated a) CMSX10-K, b) UCSX2-3Ru and c) UCSX2-5Ru.

Table II shows the composition of the as-received alloys after aluminide coating. The coating layer composition was averaged from several measurements encompassing the full coating thickness. EDX linescans confirmed a consistent $\mathrm{Al}$ concentration across each of the layers indicating that the stable phase $\beta-\mathrm{NiAl}$ had formed. The $\beta$-NiAl compound exists over a range of stoichiometries; both $\mathrm{Ru}$ bearing alloys contain a lower concentration of nickel within the coating than CMSX-10K. Comparison with the work of Rae et al. on aluminized CMSX$10 \mathrm{~K}$ prepared in the same way showed similar Al content within the coating [7]. All the alloys have a Ni/Al ratio $>1$, although in both $\mathrm{Ru}$-bearing alloys this ratio is closer to unity.

The $\beta$-layer contains precipitates which were identified by EDX as being rich in $\mathrm{Re}$ and $\mathrm{W}$, because the solid solubility of $\mathrm{W}, \mathrm{Re}$, (and $\mathrm{Mo}$ and $\mathrm{Cr}$ ) is much lower in the $\beta$-phase [8]. It is likely that these topologically close packed phases (TCP) in the as-received condition are $\mu$ phase $\left[(\mathrm{Ni}, \mathrm{Co})_{7}(\mathrm{Cr}, \mathrm{W}, \mathrm{Mo}, \mathrm{Re})_{6}\right]$ in CMSX10-K $[7,9]$ because of their morphology and the ability of $\mu$-phase to accommodate $\mathrm{Mo}$ and $\mathrm{W}$ in particular. $\alpha-\mathrm{Cr}$ precipitates have also been found in this type of coating by Tawancy et al. [10] and Angenete et al. [11] however EDX did not reveal $\mathrm{Cr}$ rich precipitates in either Ru-bearing alloy. Precipitates are present in 'waves' formed as a result of the physical breakdown of the substrate and localised dissolution of discrete pieces to produce the $\delta-\mathrm{Ni}_{2} \mathrm{Al}_{3}$ in the first stage of pack-aluminization This is retained during the final heat treatment conversion to $\beta-\mathrm{NiAl}$ [12]. In all alloys the $\beta$-NiAl surface is polycrystalline in nature, however both coated Ru-bearing alloys appear to show a greater amount of surface breaking porosity and protrusions, producing an uneven interface.

Table II. Compositional analysis of the as-coated aluminide layer and interdiffusion zone in each alloy (at-\%) determined by EDX.

\begin{tabular}{|c|c|c|c|c|c|c|}
\hline \multirow{2}{*}{ Alloy } & \multicolumn{2}{|c|}{ CMSX10-K } & \multicolumn{2}{c|}{ UCSX2-3Ru } & \multicolumn{2}{c|}{ UCSX2-5Ru } \\
\cline { 2 - 7 } & $\beta$-layer & IDZ & $\beta$-layer & IDZ & $\beta$-layer & IDZ \\
\hline $\mathrm{Ni}$ & 50.6 & 53.7 & 44.5 & 44.2 & 45.6 & 39.9 \\
\hline $\mathrm{Al}$ & 42.1 & 31.4 & 43.9 & 27.0 & 41.1 & 28.6 \\
\hline $\mathrm{Cr}$ & 1.5 & 2.7 & 1.8 & 6.0 & 2.0 & 6.2 \\
\hline $\mathrm{Co}$ & 2.6 & 3.2 & 5.9 & 9.0 & 6.2 & 8.9 \\
\hline $\mathrm{Ta}$ & 1.1 & 3.2 & 1.0 & 3.8 & 1.1 & 3.6 \\
\hline $\mathrm{Re}$ & 0.6 & 2.3 & 0.7 & 3.0 & 1.0 & 3.3 \\
\hline $\mathrm{Ru}$ & - & - & 0.8 & 2.2 & 1.6 & 5.0 \\
\hline $\mathrm{W}$ & 0.5 & 1.9 & 0.8 & 3.5 & 0.9 & 3.6 \\
\hline $\mathrm{Mo}$ & 0.2 & 0.3 & 0.3 & 0.8 & 0.2 & 0.6 \\
\hline $\mathrm{Nb}$ & - & 0.1 & - & - & - & - \\
\hline $\mathrm{Ti}$ & 0.4 & 0.6 & - & - & - & - \\
\hline $\mathrm{Hf}$ & 0.4 & 0.6 & 0.4 & 0.5 & 0.3 & 0.3 \\
\hline
\end{tabular}

The IDZ zone consists of alternating 'lamellae' of $\beta$-phase formed during final heat treatment and TCP precipitates (probably $\sigma$ $\left.(\mathrm{Ni}, \mathrm{Co})_{\mathrm{x}}(\mathrm{Cr}, \mathrm{Mo}, \mathrm{Re})_{\mathrm{y}}\right)$, before aluminium levels drop and TCPs dispersed in $\gamma^{\prime}$ (a secondary reaction zone, SRZ) are formed, and finally transition to the substrate $\gamma / \gamma$, occurs. Refractory enrichment in the IDZ compared to the substrate occurs as a result of the outward diffusion of Ni from the substrate to the coating to form the $\beta$-phase during final anneal. The edge of the IDZ bordering the coating marks the substrate-coating interface after aluminization but prior to final heat treatment at $1100^{\circ} \mathrm{C}$, and it is nearest this interface that in all three specimens TCPs are formed in the prior $\gamma$ channels, retaining their morphology. Figure 2 illustrates the IDZ in the $5 \mathrm{Ru}$ alloy, as produced by the aluminization process. 


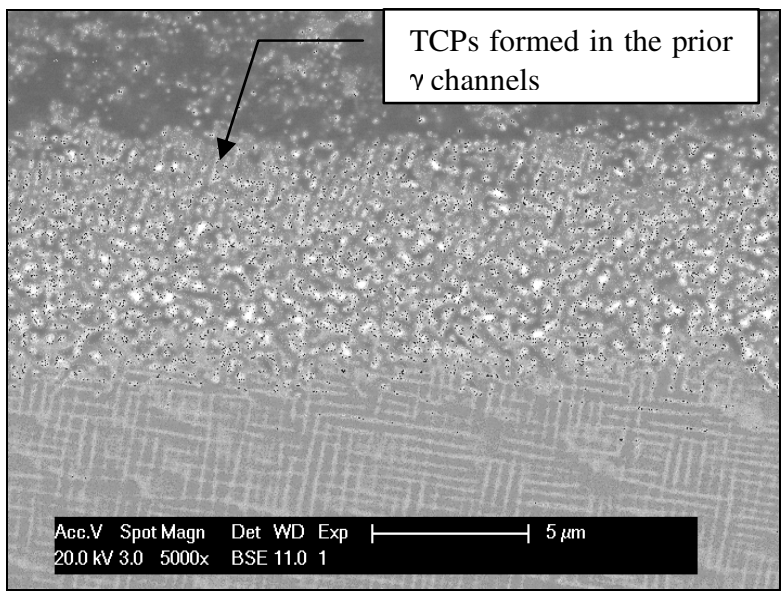

Figure 2. The IDZ in as-coated aluminized UCSX2-5Ru.

\section{Results and Discussion}

\section{The Kinetics of Oxidation}

The kinetics of oxidation of both bare and coated specimens at 750,900 and $1100^{\circ} \mathrm{C}$ are shown in Figure 3. At $750^{\circ} \mathrm{C}$ the uncoated Ru-bearing specimens both show mass-gain values an order of magnitude larger than both bare CMSX10-K and all the aluminized specimens. This faster mass-gain corresponds to the formation of $\mathrm{NiO}$ and sub-surface oxidation pits. The kinetics of oxidation of the bare alloys are discussed in detail elsewhere [13]. In both coated Ru-bearing alloys lower mass-gain values result from the prevention of formation of the internal oxidation pits seen in the uncoated alloys. Coated alloys all behaved similarly at this temperature and showed consistently high oxidation protection.

After oxidation at $900^{\circ} \mathrm{C}$, coated specimens show an order of magnitude reduction in the net mass gain when compared to the uncoated specimens, but much of this mass-gain occurs in the transient stage. The initial mass-gain during competitive oxidation is reduced in coated specimens by the relatively fast formation of a protective oxide. Figure $3 \mathrm{c}$ shows that a protective oxide is maintained on the coated specimens at $1100^{\circ} \mathrm{C}$ in contrast to the 'occasionally cycled' uncoated material, which shows significant spallation.

Published data on the kinetics of oxidation of aluminized superalloy substrates is scarce [14-16] in comparison to that of $\mathrm{NiAl}$, perhaps because they are generally considered to follow that of the bare alumina-forming substrate without the transient oxidation stage. However it is recalled that these fourthgeneration alloys are borderline alumina formers.
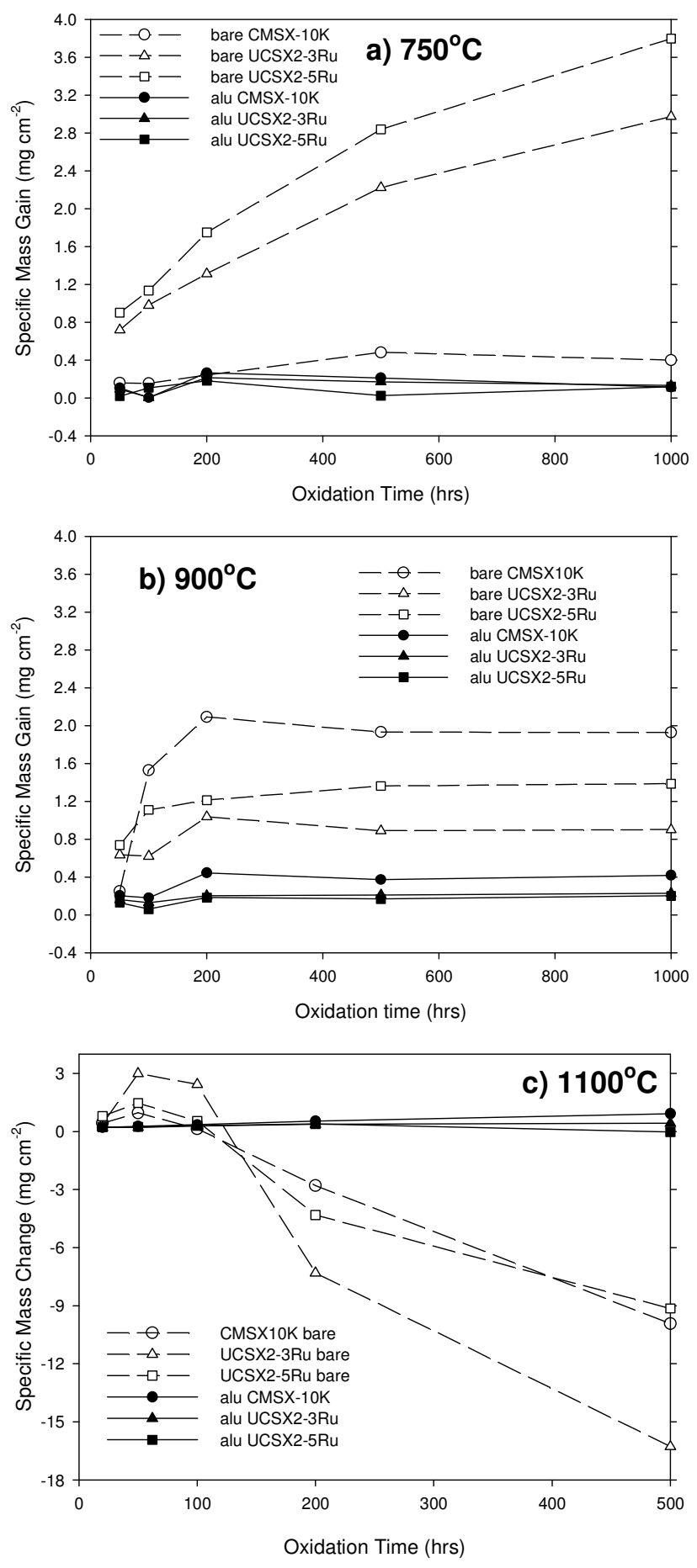

Figure 3. The net mass-gain kinetics for all three alloys, bare and aluminized at 750,900 and $1100^{\circ} \mathrm{C}$. Note that in graph c) the oxidation time only extends to 500 hours.

Closer examination of the early stages of the mass-gain curves of the aluminized samples shows the Ru-free CMSX-10K alloy has a mass-gain at 50 hours up to a maximum of an order of magnitude greater $\left(\right.$ at $750^{\circ} \mathrm{C}$ ) than the aluminized $\mathrm{Ru}$-bearing alloys at each of the temperatures tested. Increasing $\mathrm{Ru}$ content decreases the mass-pickup up to 50 hours, as shown in Figure 4, with the 
exception of $3 \mathrm{Ru}$ at $1100^{\circ} \mathrm{C}$, although this is well within the experimental scatter due to partial spallation at this temperature. These mass-gain values represent approximately half the massgain of pack-aluminized IN-738LC after the same length of oxidation at $1100^{\circ} \mathrm{C}$ [14], and approximately two orders of magnitude lower than pack-aluminized CM247 after 50h at $1100^{\circ} \mathrm{C}[15]$.

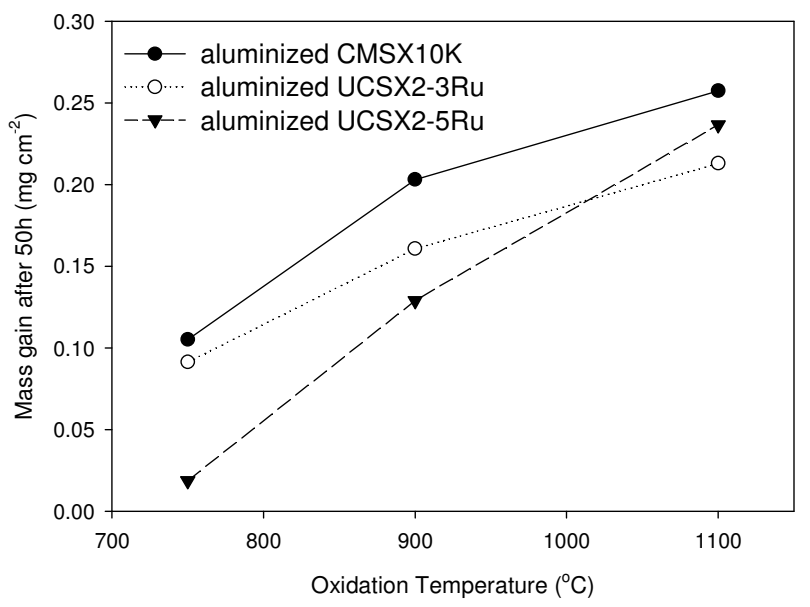

Figure 4. The specific mass gain of aluminized alloys after $50 \mathrm{~h}$ oxidation. Note that $1100^{\circ} \mathrm{C}$ specimens underwent an additional weighing at $20 \mathrm{~h}$.

Partial spallation prevented the calculation of precise parabolic rate constants from the mass-gain data. Hence estimates of the parabolic oxidation rate constant were obtained for each coated alloy at each test condition from measurements of the residual oxide thickness. Averages of approximately 50 measurements were used in each instance. Figure 5 shows the temperature dependence of these parabolic rate constants for each of the aluminized alloys. The aluminizing treatment effectively minimizes the effect of alloy chemistry on oxidation performance, at least over these timescales. It can be seen that at $1100^{\circ} \mathrm{C}$ the rates of all three samples approximate to that of $\alpha-\mathrm{Al}_{2} \mathrm{O}_{3}$. At $900^{\circ} \mathrm{C}$ the oxidation rates fall close to those of the transitional aluminas and $\mathrm{Ni}(\mathrm{Al}, \mathrm{Cr})_{2} \mathrm{O}_{4}$ (identified by $\mathrm{XRD}$ on uncoated alloys [13]) suggesting a mixture of the two. At $750^{\circ} \mathrm{C}$ the oxidation rate of the aluminized alloys is appreciably higher than that of $\gamma$ $\mathrm{Al}_{2} \mathrm{O}_{3}$. $\mathrm{Ni}(\mathrm{Al}, \mathrm{Cr})_{2} \mathrm{O}_{4}$ is the most likely candidate as the rate controlling oxide species [13]. It should be noted that although different species control the oxidation rate at the various temperatures, the absolute magnitude of the rate decreased only slightly with temperature.

\section{Characterization of Oxides}

As discussed elsewhere [13, 17], the uncoated Ru-bearing alloys exhibit sub-surface pit formation during oxidation at $750^{\circ} \mathrm{C}$ as is shown in Figure 6. The aluminized versions of these alloys show no evidence of such attack at this temperature as can be seen from Figure 7. SEM and EDX analysis shows that the external scale produced at $750^{\circ} \mathrm{C}$ on aluminized CMSX10-K is predominantly alumina and/or Ni,Al spinel (Figure 8a). Both aluminized Rubearing alloys form $\alpha-\mathrm{Al}_{2} \mathrm{O}_{3}$ and transitional aluminas (Figure $8 \mathrm{~b}$ ) together with sporadic $\mathrm{Ni}, \mathrm{Al}, \mathrm{Cr}$ spinels and some discrete $\mathrm{Cr}_{2} \mathrm{O}_{3}$ grains.

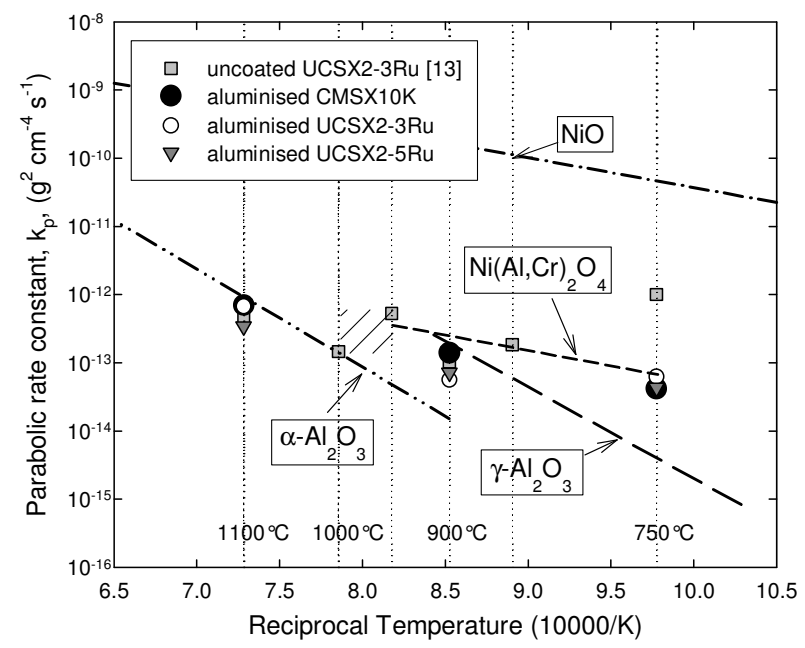

Figure 5. The temperature dependence of the parabolic rate constants for each of the aluminized alloys. Lines for the alumina polymorphs come from Grabke [18] and $\mathrm{NiO} / \mathrm{NiAl}_{2} \mathrm{O}_{4}$ from [13]. 750 and $900^{\circ} \mathrm{C}$ values are calculated over $1000 \mathrm{~h}$ oxidation, whilst $1100^{\circ} \mathrm{C}$ values are calculated over $500 \mathrm{~h} . \mathrm{K}_{\mathrm{p}}$ values at 750 $\& 900^{\circ} \mathrm{C}$ were derived using the density of $\mathrm{NiAl}_{2} \mathrm{O}_{4}$, whilst at $1100^{\circ} \mathrm{C}$ the density of $\mathrm{Al}_{2} \mathrm{O}_{3}$ was used.

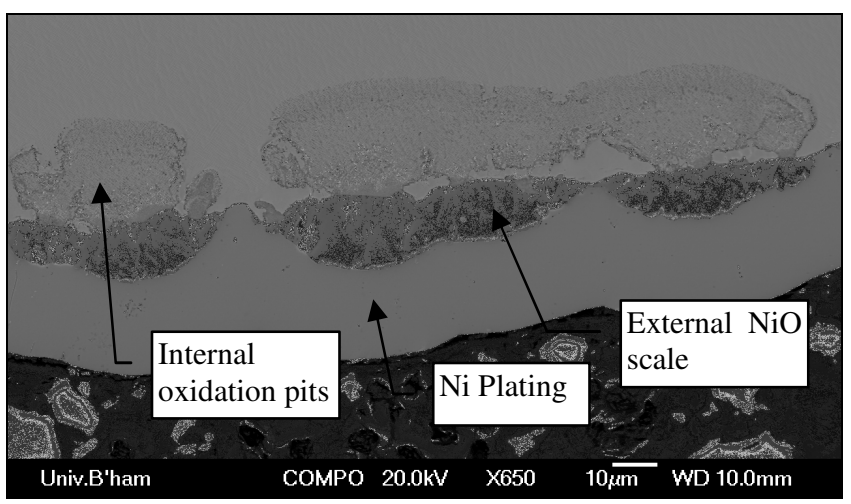

Figure 6. Internal oxidation pits found in uncoated UCSX2 alloys after oxidation at $750^{\circ} \mathrm{C}$.

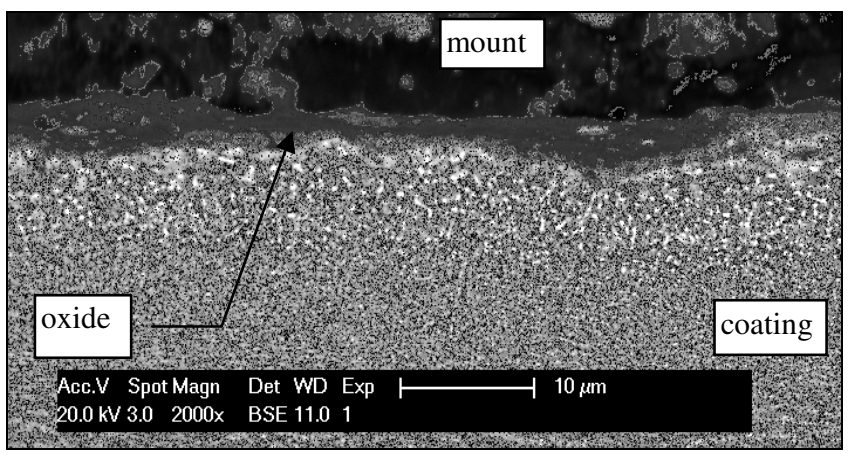

Figure 7. The surface oxide formed on aluminized UCSX2-3Ru after $1000 \mathrm{~h}$ at $750^{\circ} \mathrm{C}$. No sub-surface pits were found.

At $900^{\circ} \mathrm{C}$ surface SEM of all alloys shows pyramidal crystals of $\alpha-\mathrm{Al}_{2} \mathrm{O}_{3}$ and significant proportions of transitional $(\gamma$ and $\theta)$ 
aluminas characterized by diaphanous needle / platelet morphologies (Figure 8c,d) formed by the outward diffusion of Al. It is not possible to derive the proportions of each transitional alumina from the area fraction from micrographs for two reasons: a metastable alumina can take different forms depending on temperature [19] and transformation to $\alpha-\mathrm{Al}_{2} \mathrm{O}_{3}$ occurs from the metal/oxide interface meaning the transient alumina morphology is retained [20].

After oxidation at $750^{\circ} \mathrm{C}$ and to a lesser extent at $900^{\circ} \mathrm{C}$, mixed oxides including $\mathrm{Ni}(\mathrm{Al}, \mathrm{Cr})_{2} \mathrm{O}_{4}$ and transitional aluminas are formed, by outward cation diffusion. At $750^{\circ} \mathrm{C}$ the kinetics of oxidation are determined by transport through this $\mathrm{Ni}(\mathrm{Al}, \mathrm{Cr})_{2} \mathrm{O}_{4}$ layer. In all three alloys after oxidation at $750^{\circ} \mathrm{C}$ the outer most scale is interpenetrated by channels of porosity up to $1 \mu \mathrm{m}$ in width. This is consistent with the findings of Angenete et al. [21], but at a lower temperature. Similarly, this porosity could be found after oxidation at $900^{\circ} \mathrm{C}$ in UCSX2-3Ru, but to a lesser degree in the CMSX-10K and UCSX2-5Ru alloys where the proportion of transitional alumina apparent is higher (as suggested by Figure 5).

At $1100^{\circ} \mathrm{C}$ dense $\alpha-\mathrm{Al}_{2} \mathrm{O}_{3}$ is formed rapidly in all coated alloys, and does not appear to contain the porosity characteristic of lower temperatures. Spallation was extensive, however, as can be appreciated from Figure 8e. Transient oxide phases, reported to form on CMSX-4 with a PWA73 inward grown aluminide oxidized at $1050^{\circ} \mathrm{C}$ [22] were not observed, but may have transformed or been removed by spallation.
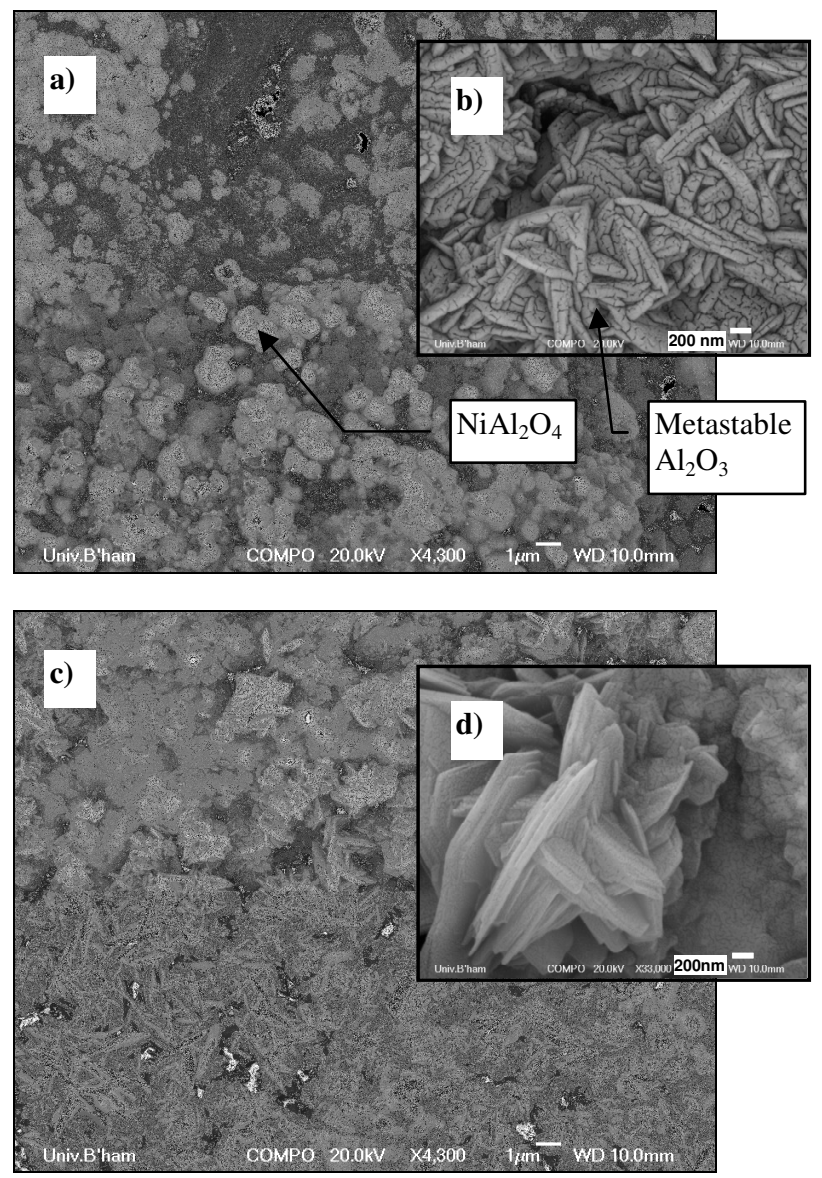

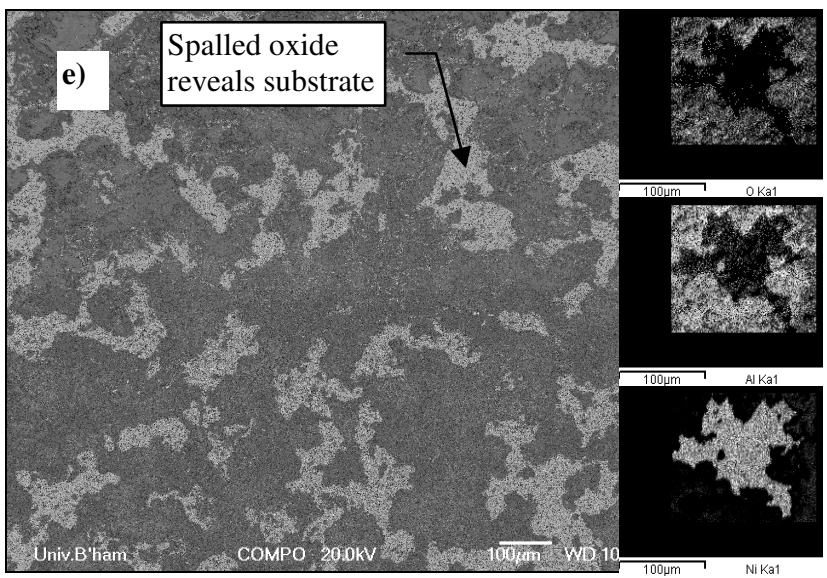

Figure 8. Backscattered electron images of the surface scale in a) aluminized CMSX-10K oxidized for $1000 \mathrm{~h}$ at $750^{\circ} \mathrm{C}$, b) aluminized UCSX2-3Ru oxidized for $1000 \mathrm{~h}$ at $750^{\circ} \mathrm{C}$, c) aluminized UCSX2-5Ru oxidized for $1000 \mathrm{~h}$ at $900^{\circ} \mathrm{C}$, d) aluminized CMSX-10K oxidized for $1000 \mathrm{~h}$ at $900^{\circ} \mathrm{C}$ and e) aluminized UCSX2-3Ru oxidized for $500 \mathrm{~h}$ at $1100^{\circ} \mathrm{C}$. Inset are $\mathrm{Ni}, \mathrm{Al}$ and $\mathrm{O}$ EDX maps of a spalled region. Note the lower magnification in image e).

X-ray diffraction confirmed the presence of predominantly $\alpha$ $\mathrm{Al}_{2} \mathrm{O}_{3}$ on the surface of aluminized CMSX-10K after $240 \mathrm{~h}$ at $1100^{\circ} \mathrm{C}$, as shown in Figure 9. No evidence of transitional aluminas was found in this sample using the same criteria as Berthome et al [23]. Substrate peaks for $\beta$-NiAl were not found in any of three scans on different areas of the sample, suggesting much of the near surface has transformed to $\gamma^{\prime}-\mathrm{Ni}_{3} \mathrm{Al}$. Comparison with cross-sectional micrographs (see below), EDX and the work of Rae et al. [7] confirms this to be the case.

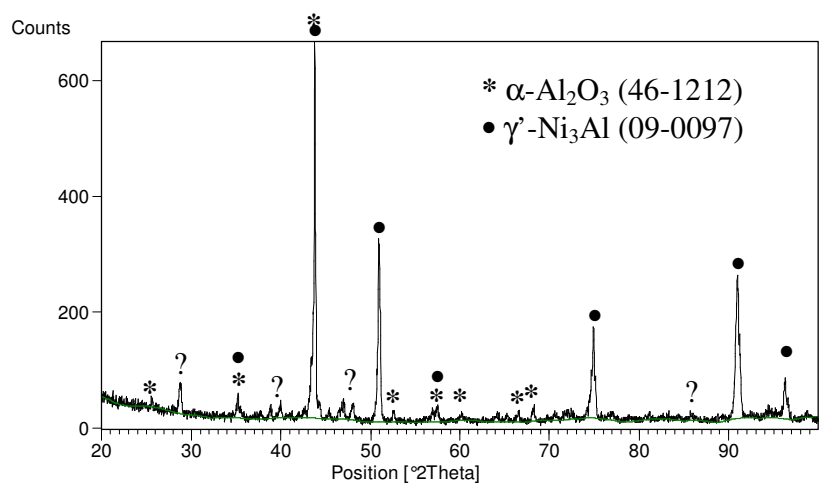

Figure 9. X-ray diffractogram of aluminized CMSX-10K after $240 \mathrm{~h}$ at $1100^{\circ} \mathrm{C}$. ? are tentatively identified as off-stoichiometric $\mathrm{TiO}_{2}$ and $\mathrm{CrTaO}_{4} / \mathrm{TaO}$.

Cyclic oxidation tests also produce a small disparity in the oxidation performance of aluminide coatings on many superalloy substrates as a function of crystallographic orientation. Poquillon et al. showed a difference between (100) and (110) orientated surfaces of single crystal $\beta$-NiAl [24], however no discernible differences could be seen in these experiments. 


\section{$\underline{\text { Oxide Spallation }}$}

$\mathrm{Mu}$ et al. [25] have shown that at $788^{\circ} \mathrm{C}$ localized spallation of metastable aluminas formed on aluminized CMSX-4 can occur within the $\beta-\mathrm{NiAl}$ grains. At higher temperatures $\alpha-\mathrm{Al}_{2} \mathrm{O}_{3}$ spallation occurs along the vaulted asperities associated with grain boundary ridges where oxidation rates are higher as a result of enhanced diffusion. The transformation of metastable fcc aluminas to the hep $\alpha-\mathrm{Al}_{2} \mathrm{O}_{3}$ by continuous ordering of $\mathrm{Al}^{3+}$, is accompanied by a $14 \%$ volume contraction that can cause cracks or voids in the scale which may lead to spallation [20]

It was not possible to draw conclusions about the spallation of these coated alloys at 750 and $900^{\circ} \mathrm{C}$ because very little spallation occurred. However after oxidation at $1100^{\circ} \mathrm{C}$ it can be seen (Figure 10a) that although some spallation may initiate from grain boundaries, spallation occurs over complete $\gamma^{\prime}$ grains without reforming any oxide, indicating it to be the result of thermal stresses due to cooling. Image analysis of BS micrographs similar to Figure 8e showed $30.3 \%$ spallation of alumina on CMSX-10K, $23.6 \%$ on UCSX2-3Ru and $58.2 \%$ on UCSX2-5Ru after removal after $500 \mathrm{~h}$ at $1100^{\circ} \mathrm{C}$. Figure $10 \mathrm{~b}$ shows the presence of numerous heavy metal TCPs in the faceted surface of $\gamma^{\prime}$ in the spalled regions. These precipitates do not appear to stand out from the coating surface indicating the vapour pressure of each are comparable. The grain structure of the oxide is inferred from the contact facets. The surface of the spalled regions is also populated by numerous Kirkendall voids formed probably as a result of $\mathrm{Al}$ consumption by the oxide.

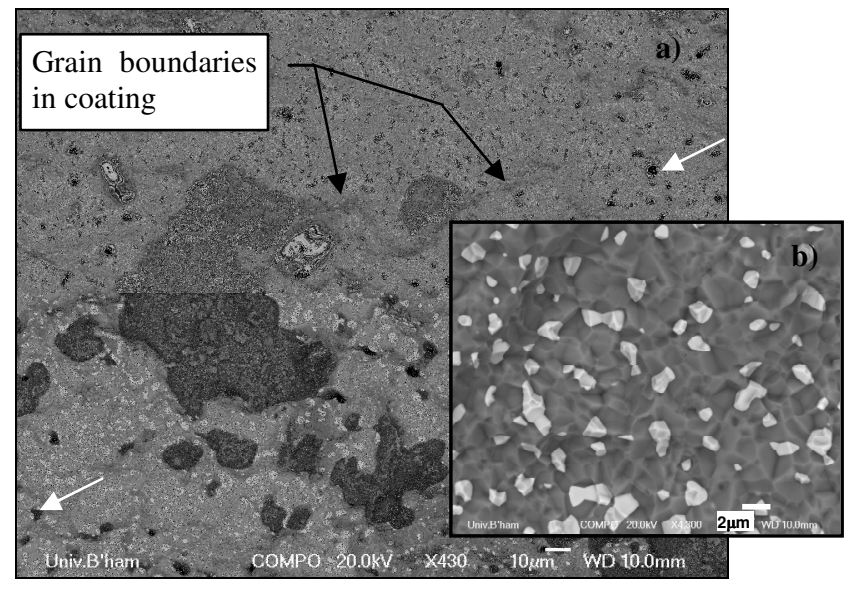

Figure 10. a) The surface scale remaining on aluminized UCSX2$5 \mathrm{Ru}$ after $500 \mathrm{~h}$ at $1100^{\circ} \mathrm{C}$. Kirkendall voids are arrowed in white, and b) a spalled region on aluminized CMSX-10K after 500h at $1100^{\circ} \mathrm{C}$. TCPs are bright in BS contrast.

\section{Coating Evolution}

Interdiffusion between the coating and substrate can destroy the $\gamma / \gamma^{\prime}$ microstructure, thereby reducing the useful metal crosssection, which can have an appreciable effect on creep life, particularly for thin wall sections. TCP precipitation can both deplete the alloy of solid-solution strengthening elements and lead to anisotropic embrittlement perpendicular to precipitate plates. Hence coating evolution was also studied as a function of temperature and alloy. Figure 11 shows the extent of coating degradation as a function of oxidation temperature and time. As expected the degradation of the coating is dramatically faster at $1100^{\circ} \mathrm{C}$. Given the comparatively close oxidation rate constants, coating thickness and coating $\mathrm{Al}$ concentration, it is not surprising that the rate of transformation of $\beta$ to $\gamma^{\prime}$ in the three alloys is also similar.

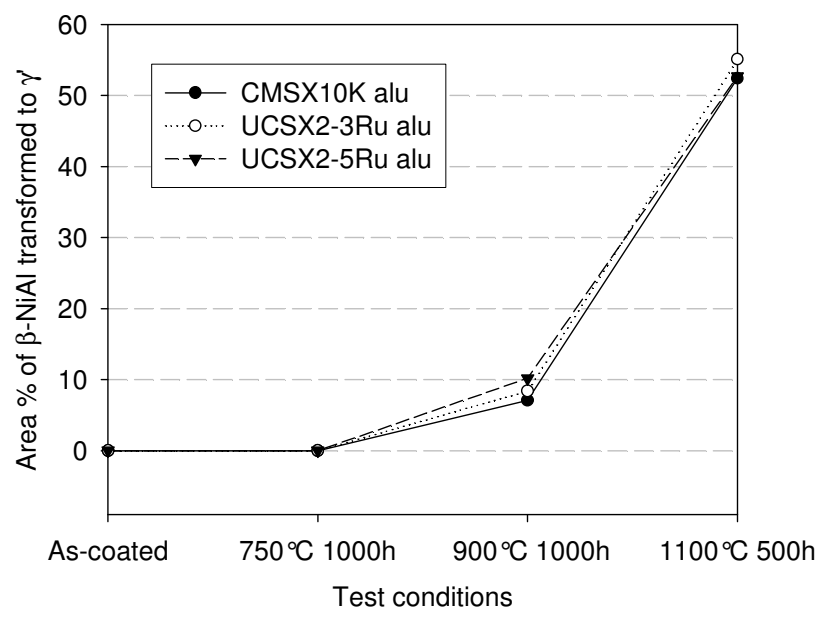

Figure 11 . The total area $\%$ of $\beta-\mathrm{NiAl}$ transformed to $\gamma^{\prime}$ within the coating layer as a function of test condition. The coating layer is

defined as bounded by the IDZ. The area fraction includes $\gamma$ ' formed at the surface and nearest the IDZ. UCSX2-3Ru showed intermediate results of $10.8 \% \gamma^{\prime}$ after $200 \mathrm{~h}$ at $1100^{\circ} \mathrm{C}$.

At $750^{\circ} \mathrm{C}$ diffusion rates are sufficiently slow as to prevent significant distinction between alloys after $1000 \mathrm{~h}$ exposure. Aluminium concentrations within the coatings are similar and interdiffusion between substrate and coating is limited. A slight thickening of the IDZ and first signs of the appearance of a secondary diffusion zone (SDZ) are apparent. No secondary reaction zone (SRZ) [26] (also termed an 'equilibriation zone' by other researchers [27]) was formed under these test conditions, and no TCPs are apparent other than those formed within the coating during the coating treatment in any of the alloys. $\mathrm{Ru}$ concentration in the coating is still much lower than the substrate.

After oxidation at $900^{\circ} \mathrm{C}$ for $1000 \mathrm{~h}$ coating evolution is in its infancy, but void formation is particularly prevalent prior to any SRZ formation. In UCSX2-5Ru the predominant resulting coating interaction is that of a SDZ, but sporadic colonies of SRZ can be found, typically nucleating at casting pores. In both Ru-bearing alloys the transformation of $\beta-\mathrm{NiAl}$ to $\gamma^{\prime}$ with $\mathrm{Al}$ depletion appears to nucleate at the TCP phases within the coating (heterogeneous nucleation), but not due to $\mathrm{Al}$ loss to the external oxide. In contrast, in CMSX-10K some $\gamma^{\prime}$ is present at the coating/oxide interface.

After exposure at both 900 and $1100^{\circ} \mathrm{C}$, 'waves' of TCPs are no longer evident in the coating microstructure - the TCPs are larger but fewer. Figure 12 confirms the reducing area fraction of precipitates with increasing temperature and time. This reflects the concomitant processes of precipitate coarsening and an increasing solubility of refractory elements in the Al-deficient $\beta$ layer and the increasing proportion of $\gamma^{\prime}-\mathrm{Ni}_{3} \mathrm{Al}$ [8]. It should be noted that the area fraction of TCPs may not be directly proportional to the volume fraction given the orientation 
relationship of TCPs with the matrix, however it can be used as a semi-quantitative indicator [28].

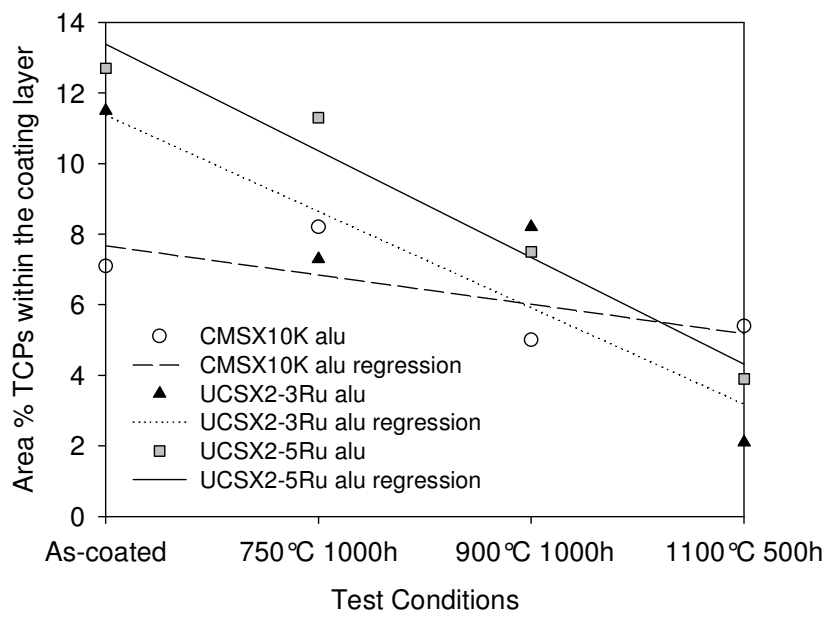

Figure 12. The area $\%$ of TCPs within the coating layer as a function of test condition. The coating layer is defined as bounded by the IDZ. UCSX2-3Ru showed intermediate results of $5.4 \%$ area fraction TCPs after $200 \mathrm{~h}$ at $1100^{\circ} \mathrm{C}$.

After oxidation for $500 \mathrm{~h}$ at $1100^{\circ} \mathrm{C}$, the coatings on all alloys show evidence of degradation (Figure 13). As Al is lost outwards to the oxide and inwards to the substrate, $\beta-\mathrm{NiAl}$ is transformed to $\gamma^{\prime}$. Both transformation interfaces between $\beta-\mathrm{NiAl}$ and $\gamma^{\prime}$ are significantly more planar in aluminized CMSX-10K than both coated Ru-bearing alloys. EDX elemental mapping (Figure 14) shows in the Ru-bearing alloys, as found by Matsuoka et al. [4], $\mathrm{Ru}$ concentrates evenly within the remaining $\beta$-phase after exposure. Comparison with the as-received coating compositions shows that the Ru must complete long-range diffusion in order to concentrate in the coating layer. Since backscattered SEM imaging did not reveal precipitates, the Ru must be in solution. $\mathrm{Ru}$ has been shown by Chao [29] to substitute favourably on the $\mathrm{Ni}$ lattice site in NiAl. However the maximum solubility of $\mathrm{Ru}$ in $\gamma^{\prime}$ is approximately 5 at\% [30], hence interestingly, in the UCSX2$5 \mathrm{Ru}$ alloy where a SRZ was present (after both 900 and $1100^{\circ} \mathrm{C}$ exposures) precipitates of $\mathrm{RuAl}$ (akin to those identified by Feng et al. [31]) could be found within the SRZ $\gamma^{\prime}$ matrix, as shown in Figure 14 and Figure 15. Matrix dilution precluded the precise compositional analysis by EDX of ' $\mathrm{RuAl}$ ' precipitates formed in aluminized UCSX2-5Ru after $500 \mathrm{~h}$ at $1100^{\circ} \mathrm{C}$. However the mean ratio of $\mathrm{Ru}: \mathrm{Al}$ content was found to be $1: 1.15$. Despite high $\mathrm{Re}$ contents in each of the alloys, the 'continuous diffusion barrier' of Re-rich precipitates in the IDZ observed in DD32 coated with an outward grown aluminide, was not seen in these alloys [16].

Each of the three alloys exhibited different coating interaction with the substrate, as shown in Figure 13. Aluminized CMSX$10 \mathrm{~K}$ formed a region of TCPs beneath the interdiffusion zone (IDZ) and, sporadically around the circumference, a layer of SRZ beneath these TCPs. Other researchers have identified these TCPs as $\sigma$-phase $[7,9,27]$. Aluminized CMSX-10K exposed for $240 \mathrm{~h}$ at $1100^{\circ} \mathrm{C}$ only showed one instance of SRZ formation beneath the layer of TCPs. The SRZ is characterized by a high angle boundary which acts as a fast diffusion path, facilitating the
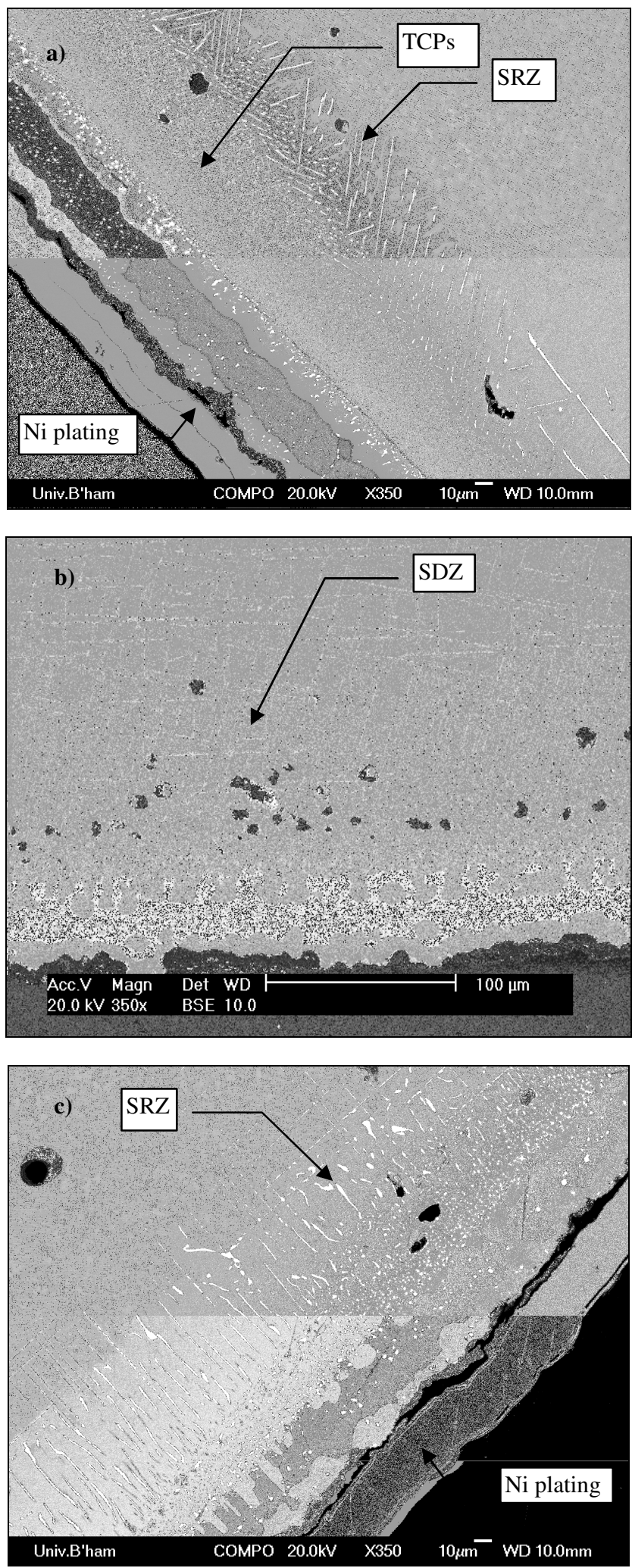

Figure 13. Backscattered SEM images of coated alloys oxidized for $500 \mathrm{~h}$ at $1100^{\circ} \mathrm{C}$ a) CMSX-10K, b) UCSX2-3Ru, c) UCSX2$5 \mathrm{Ru}$. 
discontinuous phase transformation. Aluminized UCSX2-3Ru formed only a SDZ beneath the IDZ. Kirkendall void formation is prevalent in this alloy presumably because of the flux imbalance between $\mathrm{Al}$ diffusing outwards to the oxide and inwards to the substrate and the Ni diffusing outwards into the coating. TCPs present within the SDZ are $\mathrm{Re}, \mathrm{Cr}$ and $\mathrm{W}$-rich and show fine lathe-like morphology suggesting them to be $\sigma$-phase, fitting on the alloy $\{111\}$ planes [7]. Aluminized UCSX2-5Ru forms either a SDZ or sporadically colonies of SRZ beneath the IDZ. Void formation was much less evident in this sample, possibly because the SRZ high angle boundary acts as vacancy sink. TCPs formed within the SRZ of coated UCSX2-5Ru are found to be $\mathrm{Cr}, \mathrm{Co}, \mathrm{Ni}$, $\mathrm{W}$ and Re rich. They are likely to be $\mathrm{P}$ or $\sigma$-phase [32].

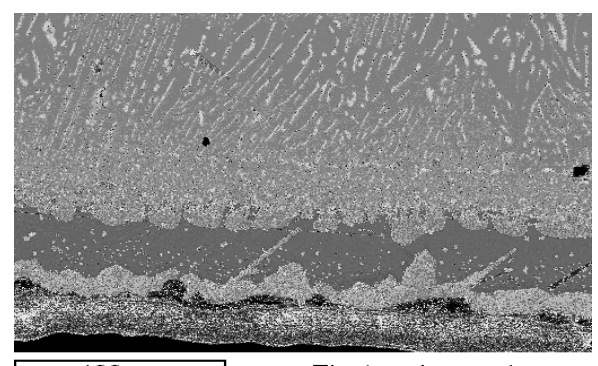

$100 \mu \mathrm{m} \quad$ Electron Image 1

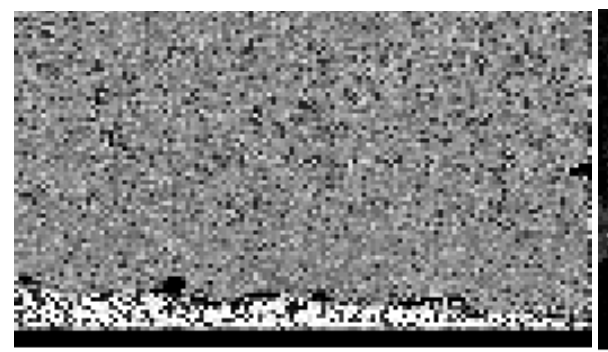

Ni Ka1

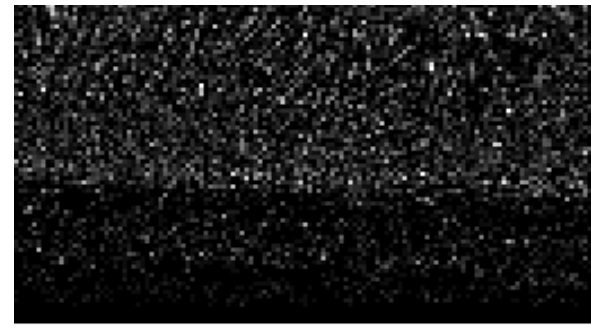

Re La1

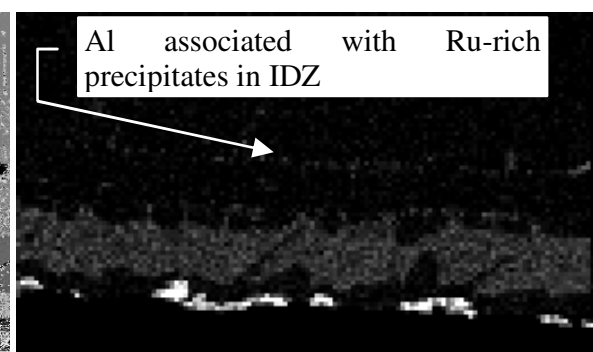

Al Ka1

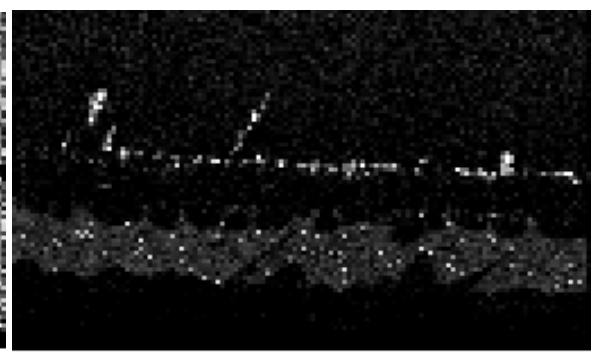

Ru La1

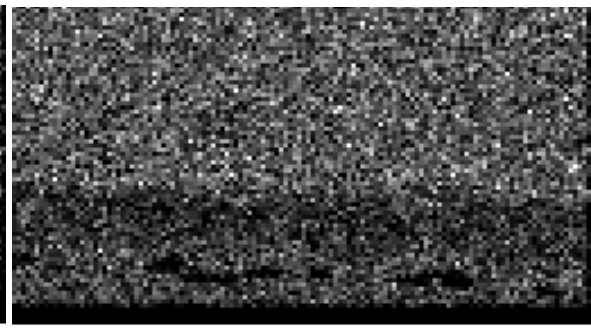

WLa1

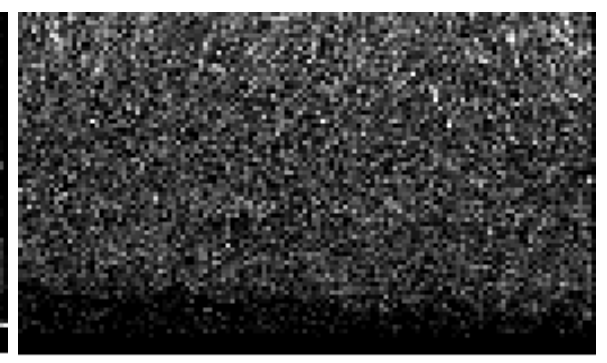

Crka1

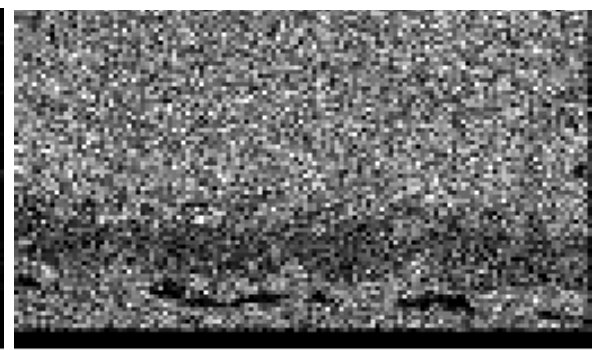

Ta La1

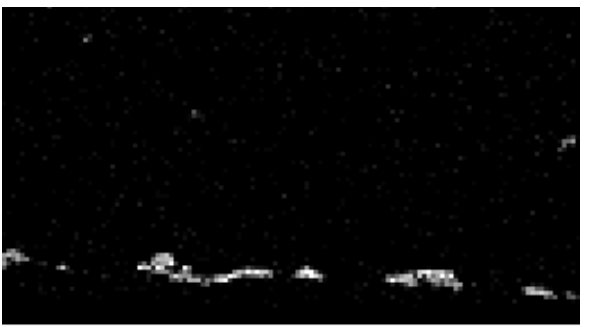

O Ka1

Figure 14. Electron image and EDX maps of aluminized UCSX2-5Ru after 500h at $1100^{\circ} \mathrm{C}$. Note the concentration of Ru in the $\beta$-layer, and RuAl precipitates within the SRZ near the IDZ interface, separate from the TCPs rich in Re, $\mathrm{Cr}$, and W.

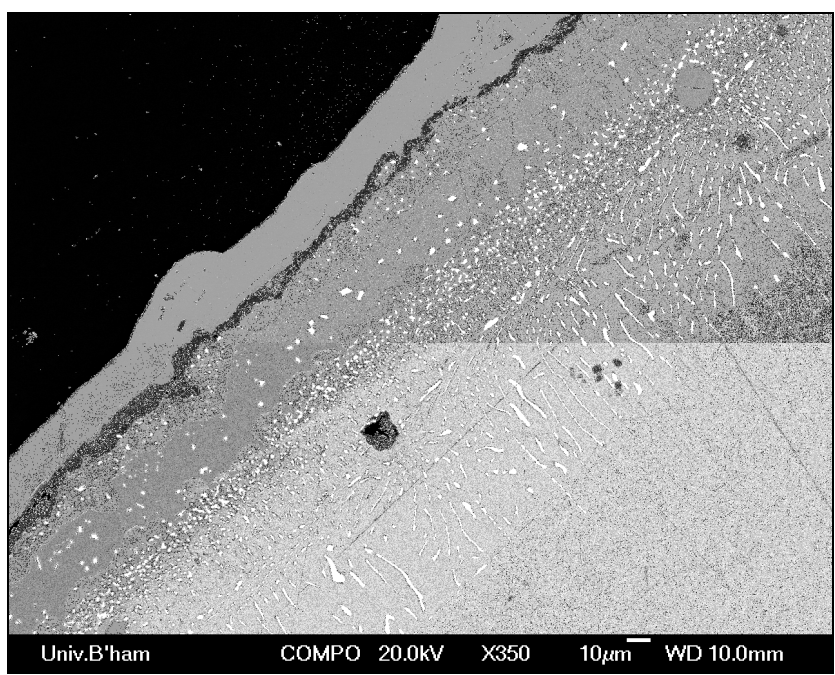

Figure 15 . UCSX2-5Ru after $1000 \mathrm{~h}$ at $900^{\circ} \mathrm{C}$ showing SRZ nucleating at a casting pore. 

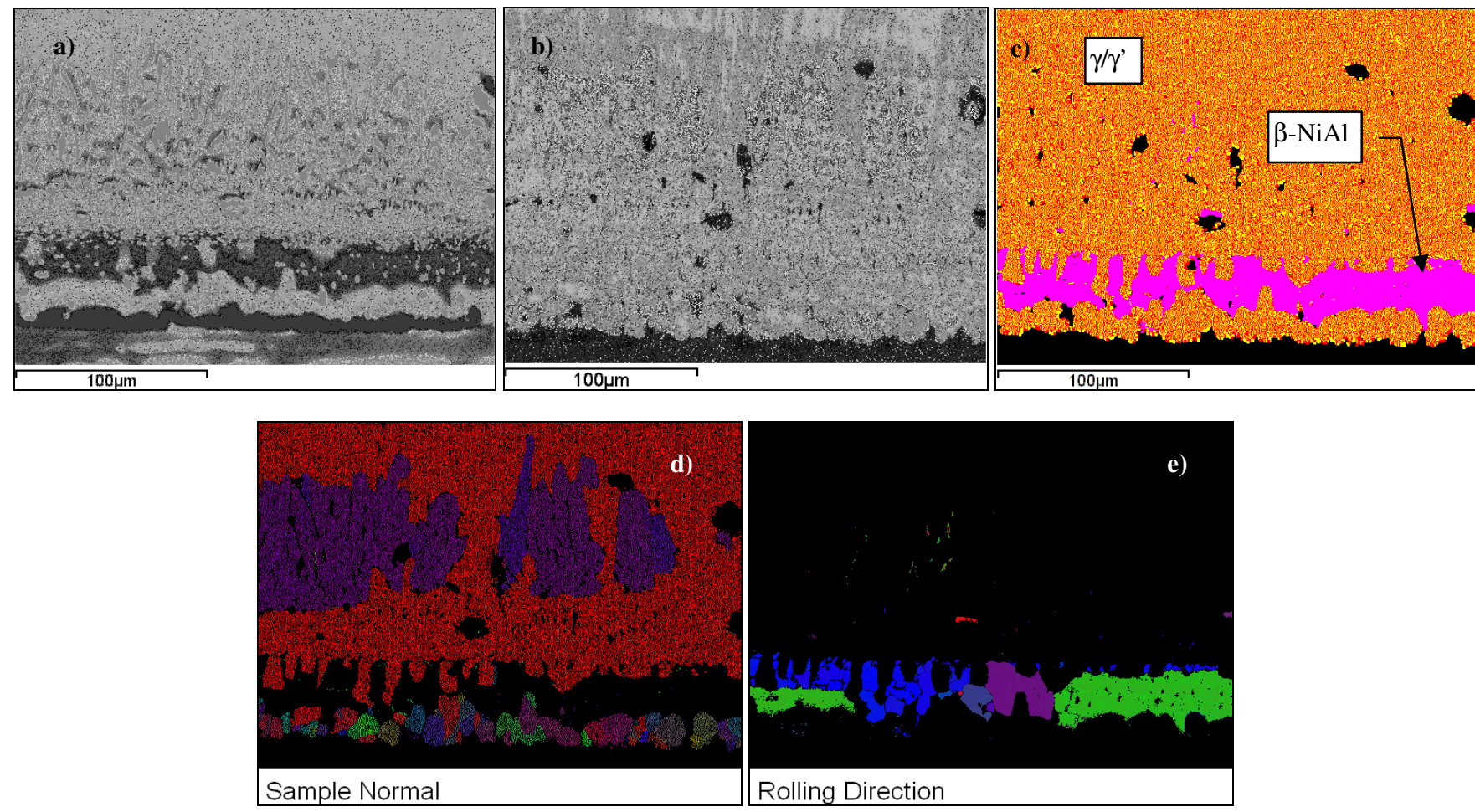

Figure 16. Aluminized UCSX2-5Ru after $500 \mathrm{~h}$ at $1100^{\circ} \mathrm{C}$; a) BS SEM image, b) EBSD pattern quality map c) EBSD crystallographic phase map, d) EBSD orientation map (sample normal) for $\gamma(\mathrm{Ni})$, showing the high angle grain boundaries of the SRZ and grains of $\gamma$ ' nucleated at the surface, e) EBSD orientation map (rolling direction, as conventionally defined for EBSD) for $\beta$-NiAl.

TCPs from the substrate SDZ often extend into the SRZ suggesting they are formed first. SRZ colonies often appear to nucleate at casting pores, as shown in Figure 15. The total depth of TCPs and SRZ in coated CMSX-10K, is comparable to the thicker SRZ formed in coated UCSX2-5Ru.

\section{Electron Backscattered Diffraction Analysis}

Figure 16 shows EBSD crystallographic phase mapping of the coated UCSX2-5Ru alloy after thermal exposure at $1100^{\circ} \mathrm{C}$. $\mathrm{Al}$ depletion does not produce a lattice parameter change from that of 50:50 stoichiometric NiAl sufficient to prevent indexing. Indeed, the depletion of $\mathrm{Al}$ from $\mathrm{NiAl}$ is expected to result in vacancy substitution on the Al sublattice [33]. However the lattice parameter difference between $\gamma / \gamma^{\prime}$ is too small to allow distinction between the two. The orientation maps show several interesting trends: firstly the $\beta$-NiAl is not single crystal in nature but contains low angle grain boundaries $\left(\sim 3^{\circ}\right.$ misorientation $)$ with both the substrate and within itself. The Ru-bearing alloys appear to contain a greater number of fast-diffusion path, higher-angle $\beta$ grain boundaries which are concurrent with 'breakthrough' $\gamma$ ' channels bridging the coating layer. $\gamma^{\prime}$ grains nucleated at the coating/oxide interface are of random orientation and can possess high angle boundaries (HABs), whilst $\gamma$ ' formed at the IDZ/ $\beta$ layer boundary tends to maintain epitaxy with the substrate, not with the $\beta-\mathrm{NiAl}$ from which it has transformed. The SRZ has approximately $38^{\circ}$ misorientation with the substrate and possesses numerous $\mathrm{HABs}$ within itself. A small amount of precipitates within the SRZ were also indexed as $\mathrm{NiAl}$ - it is proposed that these are actually precipitates of isostructural $\beta 2-\mathrm{RuAl}$ which have a similar lattice parameter. Unfortunately the pattern quality from the TCP phases was insufficient to allow phase identification.

\section{Conclusions}

The specific mass gain of aluminide coated fourth generation alloys after oxidation has been shown to be lower than that of third generation CMSX-10K. At 750 and $900^{\circ} \mathrm{C}$, Ru is shown to marginally decrease the net specific mass-gain due to oxidation in the aluminized specimens. In both Ru-bearing alloys the presence of the aluminide coating removes the propensity to form the internal oxidation pits seen in uncoated specimens. SEM and EDX analysis has revealed that mixed oxides including $\mathrm{Ni}(\mathrm{Al}, \mathrm{Cr})_{2} \mathrm{O}_{4}$ is formed at $750^{\circ} \mathrm{C}$ and to a lesser extent at $900^{\circ} \mathrm{C}$. Consideration of the oxidation rate constants shows that at $750^{\circ} \mathrm{C}$ for all alloys it is this $\mathrm{Ni}(\mathrm{Al}, \mathrm{Cr})_{2} \mathrm{O}_{4}$ which controls the oxidation rate. After oxidation at $1100^{\circ} \mathrm{C}$ a protective, predominantly $\alpha-\mathrm{Al}_{2} \mathrm{O}_{3}$, layer is maintained in all aluminized alloys. This is in contrast to the uncoated alloys which form $\alpha-\mathrm{Al}_{2} \mathrm{O}_{3}$ but show extensive massloss due to spallation upon cooling.

In both $\mathrm{Ru}$ bearing alloys, $\mathrm{Ru}$ has been shown to concentrate in solution within the $\beta$-phase after exposure at $1100^{\circ} \mathrm{C}$. In UCSX2$5 \mathrm{Ru}$ where a SRZ is formed, $\beta 2-\mathrm{RuAl}$ is precipitated within the $\gamma$ ' SRZ matrix. The coating - substrate interaction of each of the alloys studied after $500 \mathrm{~h}$ at $1100^{\circ} \mathrm{C}$ is slightly different. CMSX$10 \mathrm{~K}$ produced a layer of TCPs adjacent to the IDZ with sporadic 
SRZ beneath this. Surprisingly increasing Ru content is shown to increase the nucleation of SRZ in the Ru-bearing alloys, in contrast to the results of Walston et al. [3]. UCSX2-3Ru showed an SDZ layer beneath the IDZ but did not form a SRZ like UCSX2-5Ru. EBSD analysis shows that the $\beta$-NiAl layer on the $\mathrm{Ru}$-bearing alloys has a greater frequency of grain boundaries, increasing the susceptibility to $\gamma$ ' "breakthrough" within the coating.

\section{$\underline{\text { Acknowledgments }}$}

The author would like to thank the Engineering and Physical Sciences Research Council and Rolls-Royce Plc for funding, as part of the Engineering Doctorate scheme. Useful discussion with R.W. Broomfield, R.A. Hobbs, C.M.F. Rae and G.J. Brewster, and expert assistance with EBSD from N.P. Brewitt are gratefully acknowledged.

\section{References}

1. Sato, A., H. Harada, T. Yokokawa, T. Murakumo, Y. Koizumi, T. Kobayashi, and H. Imai, Scripta Materialia, 2006. 54(9): p. 1679.

2. Kawagishi, K., H. Harada, A. Sato, A. Sato, and T. Kobayashi, JOM, 2006. 58(1): p. 43.

3. Walston, S., A. Cetel, R. MacKay, K. O'Hara, D. Duhl, and R. Dreshfield, in Superalloys 2004. ed. K.A. Green, H. Harada, et al. Champion, PA, USA: TMS. 2004. p. 15-24.

4. Matsuoka, Y., Y. Aoki, K. Matsumoto, A. Satou, T. Suzuki, K. Chikugo, and K. Murakami, in Superalloys 2004. ed. K.A. Green, H. Harada, et al. Champion, PA, USA: TMS. 2004. p. 637.

5. Giggins, C.S. and F.S. Pettit, J. Electrochem. Soc., 1971. 118: p. 1782-1790.

6. PDF-2 Data Base (Sets 1-51 plus 70-89). Release 2001, JCPDS - International Centre for Diffraction Data, Newtown Square, PA 19073-3273 U.S.A.

7. Rae, C.M.F., M.S. Hook, and R.C. Reed, Materials Science \& Engineering A (Structural Materials: Properties, Microstructure and Processing), 2005. 396(1-2): p. 9.

8. Jia, C.C., K. Ishida, and T. Nishizawa, Metallurgical and Materials Transactions A: Physical Metallurgy and Materials Science, 1994. 25A(3): p. 485.

9. Younes, C.M., G.C. Allen, and J.A. Nicholson, Corrosion Engineering, Science and Technology, 2007. 42(1): p. 80.

10. Tawancy, H.M., N. Sridhar, N.M. Abbas, and D. Rickerby, Scripta Metallurgica et Materialia, 1995. 33(9): p. 1431.

11. Angenete, J., E. Bakchinova, and K. Stiller, in HighTemperature Corrosion and Protection of Materials. ed. R. Streiff, I.G. Wright, et al. Les Embiez, France: Trans Tech Publications Ltd. 2001. p. 663.

12. Hook, M.S., C.M.F. Rae, and R.C. Reed, in Advanced Materials and Processes for Gas Turbines. ed. G.
Fuchs, J. Allister, and T. Gabb. Copper Mountain, CO, United States: TMS. 2002. p. 179.

13. Edmonds, I.M., H.E. Evans, and C.N. Jones, in HighTemperature Corrosion and Protection of Materials. ed. P. Steinmetz, I.G. Wright et al. Les Embiez, France: Trans Tech Publications Ltd. 2008, in press.

14. Chun-Hao, K., B. Ching-Yuan, and L. Yi-Jun, Materials Chemistry and Physics, 2004. 86(2-3): p. 68.

15. Das, D.K., M. Roy, V. Singh, and S.V. Joshi, Materials Science and Technology, 1999. 15(10): p. 208.

16. Liu, C.T., X.F. Sun, H.R. Guan, and Z.Q. Hu, Surface and Coatings Technology, 2005. 194(1): p. 118.

17. Edmonds, I.M., H.E. Evans, C.N. Jones, and R.W. Broomfield, Oxidation of Metals, 2008. 69(1): p. 108.

18. Grabke, H.J., Materials Science Forum, 1997. 251254(pt 1): p. 149.

19. Doychak, J., J.L. Smialek, and T.E. Mitchell, Metallurgical Transactions A (Physical Metallurgy and Materials Science), 1989. 20A(3): p. 518.

20. Tolpygo, V.K. and D.R. Clarke, Materials at High Temperatures, 2000. 17(1): p. 59.

21. Angenete, J., K. Stiller, and V. Langer, Oxidation of Metals, 2003. 60(1-2): p. 47.

22. Svensson, H., J. Angenete, and K. Stiller, Surface and Coatings Technology, 2004. 177-178: p. 152.

23. Berthome, G., E. N'Dah, Y. Wouters, and A. Galerie, Materials and Corrosion, 2005. 56(6): p. 392.

24. Poquillon, D., D. Oquab, B. Viguier, F. Senocq, and D. Monceau, Materials Science and Engineering A, 2004. 381(1-2): p. 248.

25. Mu, N., J. Liu, J.W. Byeon, Y.H. Sohn, and Y.L. Nava, Surface and Coatings Technology, 2004. 188-189(1-3 SPECISS): p. 34.

26. Walston, W.S., J.C. Schaeffer, and W.H. Murphy, in Superalloys 1996. ed. R.D. Kissinger, D.J. Deye, et al. Champion, PA, USA: TMS. 1996. p. 9.

27. Reid, M., M.J. Pomeroy, and J.S. Robinson, Journal of Materials Processing Technology, 2004. 153-154: p. 660.

28. Angenete, J., K. Stiller, and E. Bakchinova, Surface \& Coatings Technology, 2004. 176(3): p. 83.

29. Chao, J., Acta Materialia, 2007. 55(14): p. 806.

30. Chakravorty, S. and D.R.F. West, Journal of Materials Science, 1986. 21(8): p. 30.

31. Feng, Q., T.K. Nandy, L.J. Rowland, B. Tryon, D. Banerjee, and T.M. Pollock, in Superalloys 2004. ed. K.A. Green, H. Harada, et al. Champion, PA, USA: TMS. 2004. p. 769

32. Suzuki, A., M. Yoshida, Y. Matsubara, H. Murakami, and C.M.F. Rae, in Superalloys 2008. ed. R.C. Reed, P. Caron et al. Champion, PA, USA: TMS. 2008, ibidem.

33. Lozovoi, A.Y., A. Alavi, and M.W. Finnis, Physical Review Letters, 2000. 85(3): p. 613. 